\title{
Mechanism of the Os-Catalyzed Oxidative Cyclization of 1,5-Dienes
}

\author{
Aqeel A. Hussein ${ }^{\dagger \ddagger}$, Maximillian J. S. Phipps ${ }^{\dagger}$, Chris-Kriton Skylaris ${ }^{\dagger}$, and Richard C. D. Brown ${ }^{\dagger *}$ \\ ${ }^{\dagger}$ Department of Chemistry, University of Southampton, Southampton, Hampshire, SO17 1BJ, UK \\ ${ }^{\ddagger}$ Faculty of Dentistry, University of Al-Ameed, Karbala P.O No: 198, Iraq. \\ Supporting Information Placeholder
}

\begin{abstract}
The oxidative cyclization of 1,5-dienes by metal oxo species is a powerful method for stereocontrolled synthesis of tetrahydrofuran diols (THF-diols), structural motifs present in many bioactive natural products. Oxidative cyclization of $(2 E, 6 E)$-octa-2,6-diene catalyzed by $\mathrm{OsO}_{4} / \mathrm{NMO}$ as has been studied using density functional theory (DFT) calculations (M06-2X/augcc-pVDZ/Hay-Wadt VDZ (n+1) ECP), highlighting the remarkable effect of acid on the fate of the first intermediate, an Os(VI) dioxoglycolate. Strong acid promotes cyclization of the Os(VI) dioxoglycolate, or its NMO complex, through protonation of an oxo ligand to give more electrophilic species. By contrast, in absence of acid reoxidation may occur to afford the Os(VIII) trioxoglycolate, which is shown to favor conventional "second cycle" dihydroxylation reactivity rather than cyclization. The results of the calculations are consistent with experimental results for reactions of $\mathrm{OsO}_{4} / \mathrm{NMO}$ with 1,5-dienes with acid (oxidative cyclization) and without acid (second cycle osmylation / dihydroxylation). Detailed evaluation of potential catalytic cycles support oxidation of the cyclized Os(IV) THF diolate intermediate to the corresponding Os(VI) species followed by slow hydrolysis, and finally regeneration of $\mathrm{OsO}_{4}$.
\end{abstract}

\section{INTRODUCTION}

2,5-Dihydroxyalkyl substituted tetrahydrofurans (THF-diols) are structural units present in many bioactive natural products including polyether ionophore antibiotics and Annonaceous acetogenins. ${ }^{1}$ Of the diverse methods available to synthesize THF-diols, ${ }^{2}$ oxidative cyclizations of 1,5-dienes 1 using transition-metal-oxo species stand out as one of the most direct, transforming simple starting materials into structurally complex products in a single stereoselective reaction (Scheme 1). ${ }^{3,4}$ Metal-oxo species such as $\mathrm{MnO}_{4}^{-}$, $\mathrm{OsO}_{4}$, and $\mathrm{RuO}_{4}$ react with dienes $\mathbf{1}$ to produce THF-diols 2, wherein four new $\mathrm{C}-\mathrm{O}$ bonds, and up to four new stereogenic centers can be created with control of relative stereochemistry. These reactions have been adapted to access enantio- merically enriched THF-diols by using chiral auxiliaries, ${ }^{3,5}$ chiral phase-transfer catalysis, ${ }^{6}$ or through twostep dihydroxylation-oxidative cyclization via the intermediacy of dihydroxyalkenes. ${ }^{3 \mathrm{~d}, 7}$

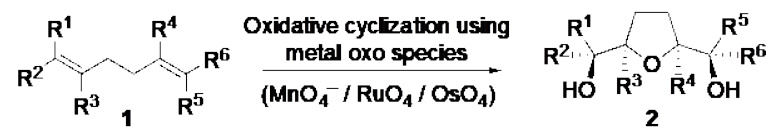

Scheme 1. Diastereoselective oxidative cyclization of 1,5-dienes 1 using metal oxo species to afford cisTHF-diols 2.

The metal-oxo species react with each double bond sequentially through stereospecific suprafacial additions of two oxygen atoms of the $\mathrm{O}-\mathrm{M}-\mathrm{O}$ moiety. Furthermore, formation of the THF ring with the 2,5-cis relationship between the hydroxyalkyl substituents occurs with high diastereoselectivity for $\mathrm{MnO}_{4}^{-},{ }^{5 \mathrm{c}, 8} \mathrm{OsO}_{4},{ }^{3 \mathrm{~d}, 9}$ and also for ruthenium-oxo oxidants under suitable conditions. ${ }^{10}$ Consequently, stereocontrolled synthesis of four possible diastereoisomeric cis THF-diol systems is attainable, stimulating numerous applications in synthesis. $3,5,9 a, 11$

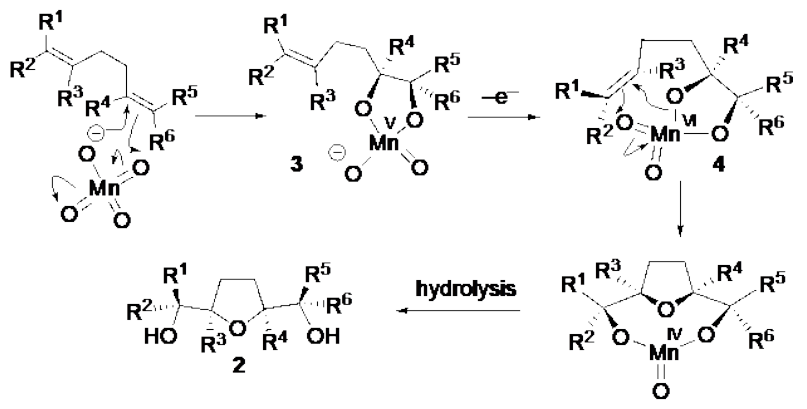

Figure 1. Baldwin's proposed mechanism for the oxidative cyclization of 1,5-dienes by permanganate.

Synthesis of cis-THF-diols 2 by oxidative cyclization of 1,5-dienes was first reported using potassium permanganate, ${ }^{8,12}$ with the related stereoselective reactions of osmium and ruthenium emerging more recently. ${ }^{9,10}$ Walba and Baldwin set out mechanistic proposals for the permanganate promoted reaction, based on either $(2+2)$ or $(3+2)$ suprafacial additions of the metal-oxo species across the olefin double bonds. ${ }^{8 a, 8 b}$ Subsequent theoretical investigations now support a $(3+2)$ pathway for the 
first reaction step (Figure 1). ${ }^{13}$ Significantly, it is the integrity of the proposed $\mathrm{Mn}(\mathrm{VI})$ glycolate intermediate 4 (or $\mathrm{Mn}(\mathrm{V})$ glycolate 3$)^{8 \mathrm{~b}, 14}$ which enforces the 2,5-cisrelationship across the incipient THF ring during cyclization. This general mechanistic proposal provides a framework for related oxidative cyclizations of $\mathrm{Ru}$ and Os oxo species, ${ }^{9,10}$ the mechanism of the latter being the focus of this paper.

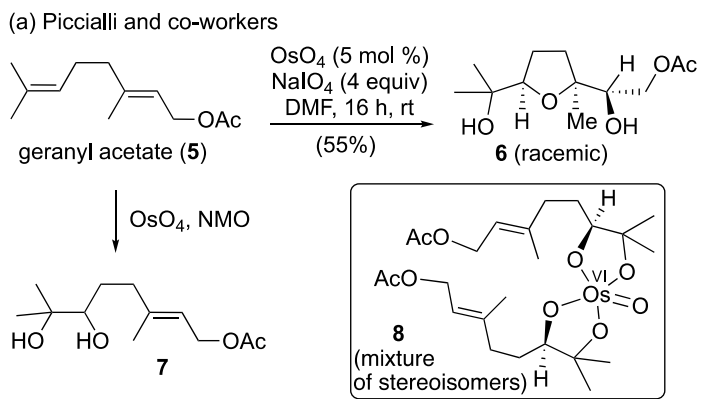

(b) Donohoe and co-workers

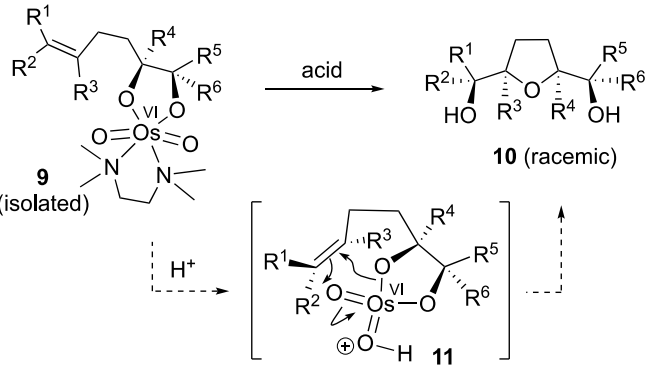

Scheme 2. (a) Os-catalyzed oxidative cyclization of 1,5-dienes using $\mathrm{OsO}_{4} / \mathrm{NaIO}_{4}$ in DMF. (b) Cyclization of Os(VI) glycolate 9 under acidic conditions, and proposed role of acid.

The first examples of oxidative cyclization of 1,5dienes by osmium tetroxide $\left(\mathrm{OsO}_{4}\right)$ were disclosed in 1998 by de Champdoré et al. using sodium periodate as a co-oxidant in DMF solution, affording racemic 2,5-cisTHF-diols (e.g. 6, Scheme 2a). ${ }^{9 c}$ Under these reaction conditions geranyl acetate (5) also gave rise to second cycle intermediate Os(VI) bisglycolate esters 8 (stereochemistry not determined). It was also shown that a low yield of THF-diol 6 (21\%) was obtained by subjecting an impure sample of 8 to $\mathrm{OsO}_{4} / \mathrm{NaIO}_{4}$ in DMF. However, when $\mathrm{NaIO}_{4}$ was replaced with $\mathrm{N}$-methylmorpholine$\mathrm{N}$-oxide (NMO) the oxidative cyclization product was not obtained and conventional dihydroxylation reactivity was restored. Indeed, dihydroxylation is the reported outcome when Upjohn $\left(\mathrm{OsO}_{4} / \mathrm{MNO}\right)$, or Sharpless asymmetric dihydroxylation conditions are applied to dienes and polyenes. ${ }^{15}$

During their studies on directed osmylation of alkenes Donohoe and co-workers discovered that acid treatment of osmium(VI) glycolate complex $\mathbf{9}$ yielded a cis-THFdiol 10 rather than the anticipated decomplexed diol (Scheme $2 \mathrm{~b}){ }^{\mathrm{gb}}$ It was proposed that the acid serves either to promote rapid ligand exchange to allow cyclization, or to protonate an oxo-ligand, giving rise to a more electrophilic osmium-oxo species 11, capable of addition across the remaining double bond. Recognition of the important role of acid in promoting cyclization led to development of catalytic methods for oxidative cyclization of 1,5-dienes as well as related cyclizations of dihydroxyalkenes. ${ }^{3 \mathrm{~d}, 7 \mathrm{c}, 7 \mathrm{~d}, 9 \mathrm{a}}$ Notably, efficient osmiumcatalyzed oxidative cyclization of 1,5-dienes using $\mathrm{Me}_{3} \mathrm{NO}$ as co-oxidant requires acidic or Lewis-acid conditions. ${ }^{3 \mathrm{~d}, 9 a}$ Similarly, osmium-catalyzed oxidative cyclization of dihydroxyalkenes also requires an excess of Bronsted acid or Lewis-acid, and is most effective when a weaker co-oxidant (pyridine $N$-oxide) is used to avoid re-oxidation of Os(VI) $\rightarrow \mathrm{Os}(\mathrm{VIII})$, restricting the reaction to an Os(VI)/Os(IV) cycle. ${ }^{3 \mathrm{~d}, 7 \mathrm{c}}$

Oxidative cyclization of 1,5-dienes has been the subject of several computational studies, ${ }^{14,16,17}$ and one of them concerns the osmium-mediated reaction. ${ }^{16}$ In 2010, Poethig and Strassner reported a DFT (B3LYP) study of the oxidative cyclization of 1,5-dienes by osmium tetroxide. ${ }^{16}$ The mechanistic framework is built around two key steps; alkene osmylation (first reaction step, FRS, Figure 2) and cyclization to form the THF ring (second reaction step, SRS). Osmylation (FRS) has been studied previously in the context of olefin dihydroxylation, and leads initially to Os(VI) glycolate intermediates through a $(3+2)$ pathway. ${ }^{18}$ For the SRS the oxidation states of intermediate Os-glycolate (VI or VIII) and possible ligand coordination were considered.

Their calculations support a pathway from $\mathrm{OsO}_{4}$, $\mathrm{Os}(\mathrm{VIII}) \rightarrow \mathrm{Os}(\mathrm{VI}) \rightarrow \mathrm{Os}(\mathrm{VIII}) \rightarrow \mathrm{Os}(\mathrm{VI})$, including an intermediate exergonic oxidation of initially formed Os(VI) glycolate to Os(VIII). Cyclization of the Os(VIII) glycolate was calculated to proceed with a reduced activation energy barrier in comparison to the Os(VI) intermediate.

Overall, these DFT studies are in accord with the general mechanistic proposal for the oxidative cyclization of 1,5-dienes by $\mathrm{OsO}_{4}$. However, we believe that important experimental observations are not accounted for. Most significantly, the role of acid (Bronsted or Lewis) was not considered; the SRS is known to be viable through an Os(VI) intermediate (see Scheme 2b) under acidic conditions. ${ }^{3 \mathrm{~d}}$ Furthermore, when acid is not present, oxidation of 1,5-dienes (and polyenes) catalyzed by $\mathrm{OsO}_{4}$ using $\mathrm{NMO}$ as the terminal oxidant do not result in oxidative cyclization, and normal dihydroxylation is observed. ${ }^{15}$ Yet, under these "Upjohn conditions" reoxidation to form an Os(VIII) trioxoglycolate intermediate is inferred by the observation second cycle intermediates. ${ }^{19}$ Therefore, the conclusion that the reaction proceeds through direct cyclization of an Os(VIII) intermediate seemed doubtful to us, or at least, incomplete. In the current work, we describe a DFT study of the Oscatalyzed oxidative cyclization of 1,5-dienes, leading to a detailed description of the mechanism, which is consistent with experimental observations and highlights the important role of acid in the reaction. We also evaluate subsequent steps leading to release of THF-diol product and propagation of a catalytic cycle. 


\section{RESULTS AND DISCUSSION}

Oxidative cyclization of (2E,6E)-octa-2,6-diene (12) to give $\left(1 S^{*}, 1^{\prime} R^{*}\right)-1,1^{\prime}-\left(\left(2 R^{*}, 5 S^{*}\right)\right.$-tetrahydrofuran-2,5diyl)diethanol (THF-diol 13) was investigated using the M06-2X/aug-cc-pVDZ/Hay-Wadt VDZ (n+1) ECP level of theory with acetone as a representative medium (SMD solvation model). ${ }^{20,21}$ The reaction pathway is considered as two principal steps: $(3+2)$ cycloaddition of $\mathrm{OsO}_{4}$ with one of the diene double bonds (FRS, Figure 2 ), and addition of resulting Os glycolate species across the remaining alkene (SRS). Alkene osmylation has been the subject of previous DFT studies, ${ }^{18}$ so our main focus here is the SRS, and possible secondary reactions that may occur prior to cyclization under conditions commensurate with experimental protocols.

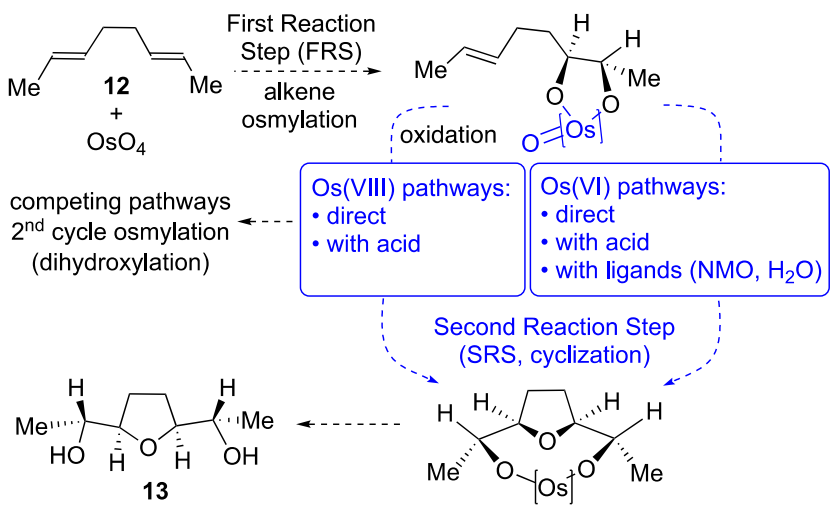

Figure 2. Summary of pathways considered for oxidative cyclization of 1,5-diene 12 by $\mathrm{OsO}_{4}$.

The reaction manifolds considered for the initially formed intermediate, Os(VI) dioxoglycolate, include:

- cyclization of Os(VI) glycolate with or without acid

- cyclization of liganded $\left(\mathrm{H}_{2} \mathrm{O}\right.$ or NMO) Os(VI) glycolates with or without acid

- oxidation (Os(VI) $\rightarrow$ Os(VIII)) followed by cyclization of resulting Os(VIII) glycolate with or without acid, or participation in the "second cycle" (dihydroxylation)

These pathways are discussed below.

Oxidative cyclization of $\mathrm{Os}(\mathrm{VI})$ dioxoglycolate intermediates with and without acid.

First, oxidative cyclization of 1,5-diene 12 by $\mathrm{OsO}_{4}$ was considered with and without acid (Figure 3). Low spin pathways are favored according to the calculations, which is in accord with the electronic configurations of Os(VI) oxoglycolates. ${ }^{22,23}$ Osmylation of diene 12 leads to tetrahedral Os(VI) dioxoglycolate $\mathbf{1 5}$ by way of $(3+2)$ cycloaddition TS $\mathbf{1 4}$ with a free energy barrier of 17.6 $\mathrm{kcal} / \mathrm{mol}$ as an exergonic reaction $\left(\Delta \mathrm{G}_{\mathrm{osm}}=-42.0\right.$ $\mathrm{kcal} / \mathrm{mol}) .{ }^{24}$ The SRS proceeds from tetrahedral Os(VI) dioxoglycolate 15 to Os(IV) THF diolate 17 by addition of $\mathrm{O}-\mathrm{Os}=\mathrm{O}$ across the remaining alkene through TS $\mathbf{1 6}$ with a barrier of $25.2 \mathrm{kcal} / \mathrm{mol}$ as an exergonic step $\left(\Delta \mathrm{G}_{\mathrm{cyc}}=-24.4 \mathrm{kcal} / \mathrm{mol}\right)$.

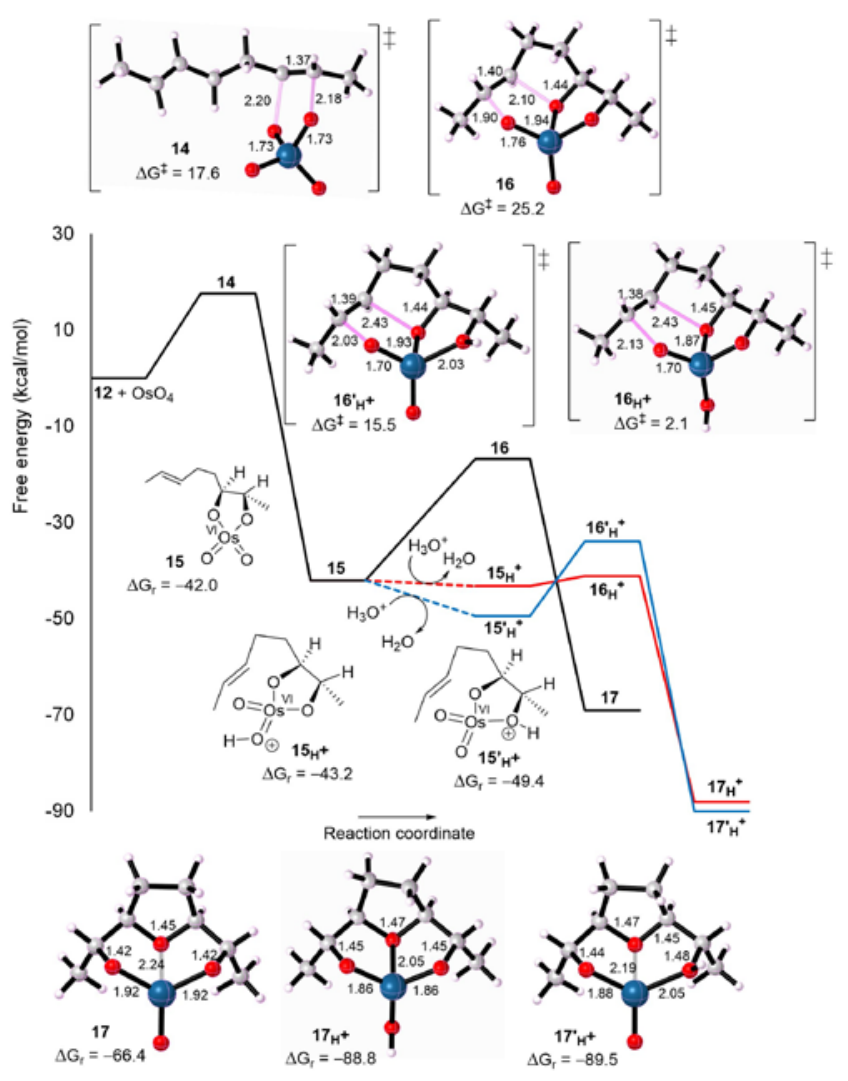

Figure 3. Free energy profile for the oxidative cyclization of 1,5-diene 12 by $\mathrm{OsO}_{4}$, showing the effect of acid on cyclization and regioselectivity of protonation: $15 \rightarrow 15 \mathrm{H}^{+}$and $15 \rightarrow 15{ }^{\prime} \mathrm{H}^{+}$. Selected structures for TS's and reaction intermediates are shown. Os(VI) dioxoglycolate 15 calculated in a reactive conformation for the SRS. For conformational analysis, see SI.

The influence of Bronsted acid was investigated, exploring the proposal that protonation of the first intermediate Os(VI) dioxoglycolate $\left(\mathbf{1 5} \rightarrow \mathbf{1 5}_{\mathbf{H}^{+}} / \mathbf{1 5}{ }^{\mathbf{H}^{+}}{ }^{+}\right)$offers a viable pathway for cyclization. $\mathrm{H}_{3} \mathrm{O}^{+}$is introduced into the calculations as a representative strong acid, commensurate with experimental conditions optimized for oxidative cyclization by Donohoe and co-workers (e.g. 5 equiv CSA or TFA). It is found that protonation of an oxo ligand by $\mathrm{H}_{3} \mathrm{O}^{+}$to give $\mathbf{1 5}_{\mathrm{H}^{+}}$is approximately thermoneutral $\left(\Delta \mathrm{G}_{\mathrm{H}^{+}}=-1.2 \mathrm{kcal} / \mathrm{mol}\right.$, Figure 3), but the effect on the barrier to cyclization is substantial. The protonated $\mathrm{Os}(\mathrm{VI})$ pathway displays a relative stabilization of TS $\mathbf{1 6}_{\mathbf{H}^{+}}$in comparison to $\mathbf{1 6}$, proceeding with a lower barrier of $2.1 \mathrm{kcal} / \mathrm{mol}$ as an exergonic reaction $\left(\Delta \mathrm{G}_{\mathrm{cyc}}=-45.6 \mathrm{kcal} / \mathrm{mol}\right)$. Glycolate protonated tautomer ${ }^{15}{ }^{\prime} \mathbf{H}^{+}$is more stable relative to $\mathbf{1 5}_{\mathbf{H}^{+}}$, but exhibits an increased barrier for cyclization of $15.5 \mathrm{kcal} / \mathrm{mol}$.

The PES calculations were validated by molecular dynamics (MD) simulations performed at the same level of theory. MD simulations highlighted the asynchronous nature of $(3+2)$ cyclizations during the SRS, showing development of the $\mathrm{C}-\mathrm{O}[\mathrm{THF}]$ bond lagging behind the $\mathrm{C}-\mathrm{O}[\mathrm{Os}]$ bond (for full details, see $\mathrm{SI}$ ).

Cyclization of liganded Os(VI) Intermediates 
Other pathways are possible for cyclization including addition of water or NMO to the intermediate $\mathbf{1 5}$ with or without acid. Without acid (Figure 4), pentacoordinate intermediates $\mathbf{1 5}_{\mathrm{H} 2 \mathrm{O}}$ or $\mathbf{1 5}_{\mathrm{NMO}}$ are formed with modest exergonicity $\left(\Delta \mathrm{G}_{\text {lig }}=-4.2\right.$ and $-5.1 \mathrm{kcal} / \mathrm{mol}$, respectively). The overall reaction from $\mathbf{1 5}_{\mathbf{H} 2 \mathrm{O}}$ to THF-Os(IV) complex $\mathbf{1 7}_{\mathbf{H} 2 \mathrm{O}}$ remains thermodynamically favorable $\left(\Delta \mathrm{G}_{\mathrm{cyc}}=-18.3 \mathrm{kcal} / \mathrm{mol}\right)$, but requires an energy barrier of $29.5 \mathrm{kcal} / \mathrm{mol}$ to be overcome via distorted trigonal bipyramidal $(3+2)$ cycloaddition TS $\mathbf{1 6} \mathbf{H}_{\mathbf{2}}$. A higher barrier to cyclization is found for $\mathbf{1 5}_{\mathrm{NMO}}\left(\Delta \mathrm{G}^{\ddagger}=36.0\right.$ $\mathrm{kcal} / \mathrm{mol}$, TS $\mathbf{1 6}_{\mathrm{NMO}}$ ), proceeding with modest exergonicity $\left(\Delta \mathrm{G}_{\mathrm{cyc}}=-7.0 \mathrm{kcal} / \mathrm{mol}\right)$.

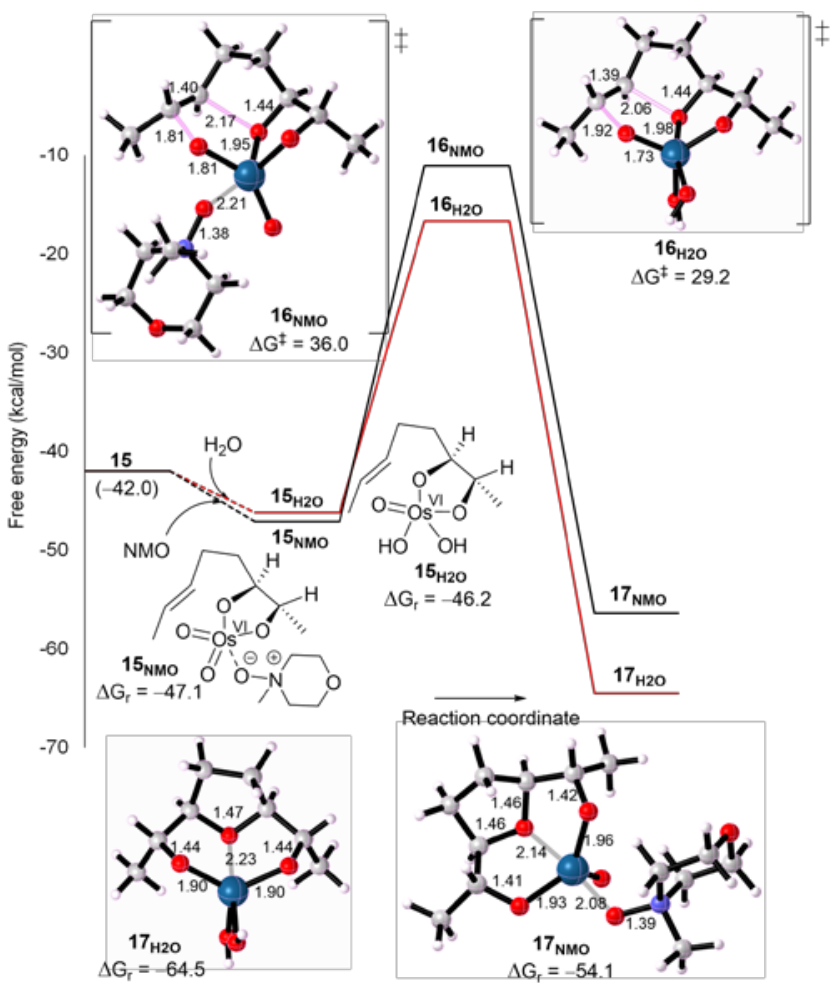

Figure 4. Cyclization of $\mathrm{Os}(\mathrm{VI})$ glycolates with $\mathrm{H}_{2} \mathrm{O}$ $(15 \rightarrow 15 \mathrm{H} 2 \mathrm{O})$ and NMO $(15 \rightarrow 15 \mathrm{NMO})$

Protonation of liganded Os(VI) oxoglycolates $\mathbf{1 5}_{\mathbf{H} 2 \mathrm{O}}$ and $\mathbf{1 5}_{\mathrm{NMO}}$ is highly exergonic, with a substantial effect on subsequent barriers to cyclization (Figure 5). Protonation of an $\mathrm{OH}$ group in $\mathbf{1 5}_{\mathrm{H} 2 \mathrm{O}}$ provides a stabilization of $19.8 \mathrm{kcal} / \mathrm{mol}$, and $\mathbf{1 5}_{\mathbf{H}^{+}} \mathbf{H}_{20}$ cyclizes with a reduced barrier of $11.7 \mathrm{kcal} / \mathrm{mol}\left(\mathrm{TS} \mathbf{1 6}_{\mathbf{H}^{+}} \mathbf{H}_{\mathbf{2}}\right.$ ) as an exergonic reaction $\left(\Delta \mathrm{G}_{\mathrm{cyc}}=-38.2 \mathrm{kcal} / \mathrm{mol}\right)$. Protonation of $\mathbf{1 5}_{\mathrm{NMO}}$ is comparatively more favorable, with preference for oxo protonation $\left(\mathbf{1 5}_{\mathrm{NMO}} \rightarrow \mathbf{1 5}_{\mathrm{H}^{+}}{ }_{\mathrm{NMO}}, \Delta \mathrm{G}_{\mathrm{H}^{+}}=-51.4\right.$ $\mathrm{kcal} / \mathrm{mol}$ ). Cyclization of $\mathbf{1 5}_{\mathrm{H}^{+}}{ }_{\mathrm{NMO}}$ to Os(IV) THF diolate $\mathbf{1 7}_{\mathrm{H}^{+}}{ }_{\mathrm{NMO}}$ shows a barrier of $18.5 \mathrm{kcal} / \mathrm{mol}$ via TS $16 \mathrm{H}^{+}$NMO and a reaction free energy of $\Delta \mathrm{G}_{\mathrm{cyc}}=-19.1$ $\mathrm{kcal} / \mathrm{mol}$. The alkoxy protonated isomer ${ }^{15}{ }^{\mathbf{H}^{+}}{ }_{\mathrm{NMO}}$ is less stable than $15_{\mathrm{H}^{+}}{ }_{\mathrm{NMO}}$ by $28.8 \mathrm{kcal} / \mathrm{mol}$ although it exhibits a slightly reduced barrier to cyclization of 17.9 $\mathrm{kcal} / \mathrm{mol}$ (see SI).

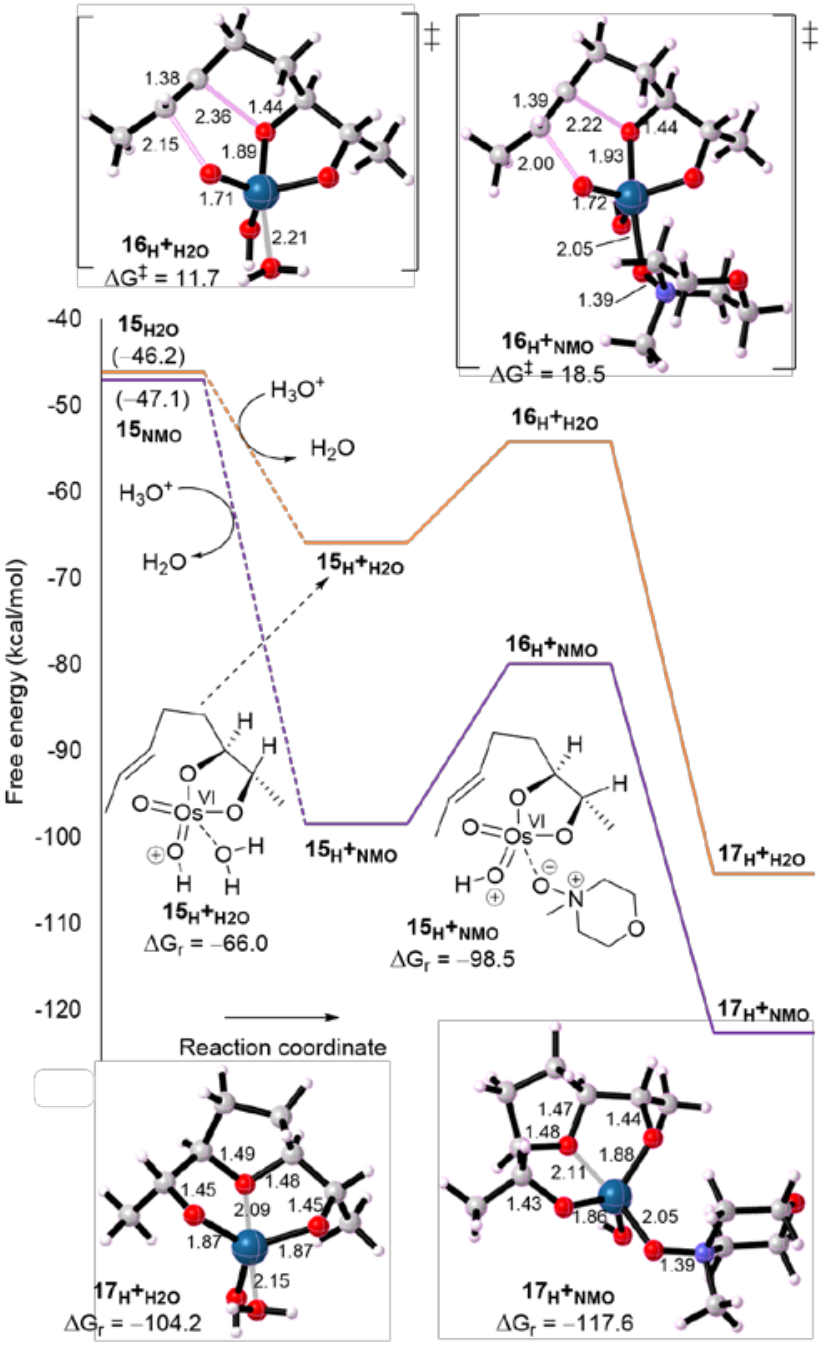

Figure 5. Cyclization of liganded Os(VI) glycolates in acid with $\mathrm{H}_{2} \mathrm{O}\left(15 \rightarrow 15 \mathrm{H}^{+} \mathrm{H}_{2}\right)$ and NMO $(15 \rightarrow 15$ $\left.\mathrm{H}^{+} \mathrm{NMO}\right)$.

Reoxidation pathways (Os(VI) $\rightarrow \mathrm{Os}(\mathrm{VIII}))$

Although Os(VIII) trioxoglycolates have yet to be characterized, their formation by oxidation of Os(VI) dioxoglycolates is widely accepted in Os-catalyzed processes. ${ }^{19}$ In this work, reoxidation of $\mathbf{1 5}$ is investigated as two elementary steps (NMO complexation and oxotransfer, Figure 6), in the presence or absence of strong acid. ${ }^{25}$ Formation of NMO complex $\mathbf{1 5}_{\text {NMO }}$ precedes dissociation of the $\mathrm{N}-\mathrm{O}$ bond to release Os(VIII) species $\mathbf{1 5}_{[\mathbf{o x}]}$ and $\mathrm{N}$-methylmorpholine (NMM) as an endergonic overall process $\left(\mathbf{1 5} \rightarrow \mathbf{1 5}_{\mathrm{NMO}}, \Delta \mathrm{G}_{\mathrm{ox}}=16.8\right.$ $\mathrm{kcal} / \mathrm{mol}$ ). We were unable to locate a transition state for oxo-transfer using transition state search of quantum calculations. ${ }^{26}$ None the less, the reoxidation by NMO should be a relatively slow step, which is consistent with reported kinetic data. ${ }^{27}$

If it is accepted that re-oxidation of Os(VI) dioxoglycolate occurs, ensuing cyclization of $\mathbf{1 5}_{[\text {[ox] }}$ to $\mathbf{1 7}_{\text {[ox] }}$ via the distorted square pyramidal $(3+2)$ cycloaddition TS $\mathbf{1 6}_{[\mathbf{o x}]}$ has a comparatively lower activation energy barri- 
er $(11.8 \mathrm{kcal} / \mathrm{mol})$ than without reoxidation $(\mathbf{1 5} \rightarrow \mathbf{1 7}$, $25.2 \mathrm{kcal} / \mathrm{mol})$.

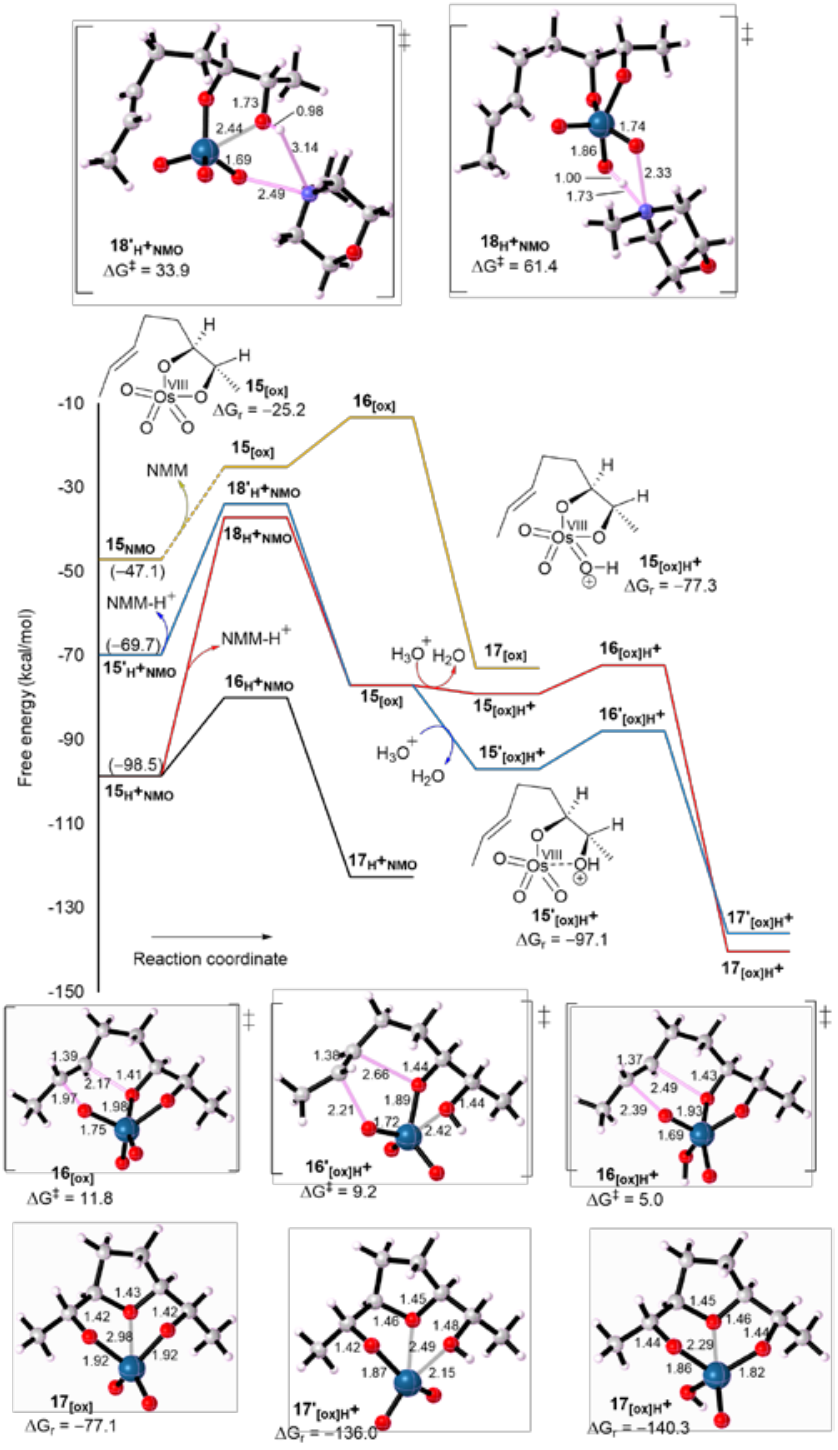

Figure 6. Cyclization of Os(VIII) glycolates; with acid

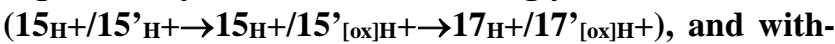
out acid $\left(15_{[0 x]} \rightarrow 17_{[o x]}\right)$. Black line shows cyclization of $15_{\mathrm{H}^{+}}{ }_{\mathrm{NMO}}(\mathrm{Os}(\mathrm{VI}))$.

In order to take into account the effect of strong acid $\left(\mathrm{H}_{3} \mathrm{O}^{+}\right)$, on Os(VIII) pathways, its influence on both reoxidation and cyclization should be considered. Protonation of NMO complex $\mathbf{1 5}_{\mathrm{NMO}}$ is strongly favored (vide supra, Figure 5). However, oxo-transfer from $\mathrm{N}$ to Os requires a very substantial barrier of $61.4 \mathrm{kcal} / \mathrm{mol}$ to be overcome and is again an endergonic step (Figure 6), despite facilitation by release of $\mathrm{NMM}-\mathrm{H}^{+}$. However, should it be formed, Os(VIII) glycolate $\mathbf{1 5}_{\text {[ox] }}$ would undergo exergonic re-protonation by $\mathrm{H}_{3} \mathrm{O}^{+}$and cyclization with a barrier of $9.2 \mathrm{kcal} / \mathrm{mol}$

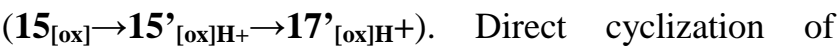
$15_{\mathrm{H}^{+}}{ }_{\mathrm{NMO}}$ to the THF-diolate $17_{\mathrm{H}^{+}}{ }_{\mathrm{NMO}}$ is shown in Figure 6 for comparison, as an exergonic reaction with a lower barrier. Therefore, on the basis of the M06-2X calculations, we conclude that cyclization is favored over reoxidation when strong acid is present.

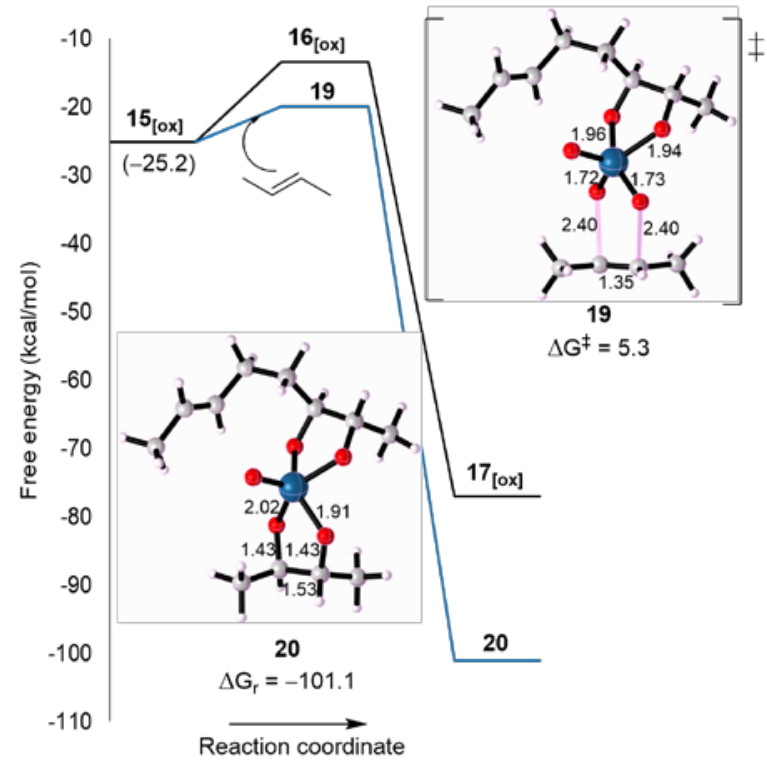

Figure 7. Energetic comparison between cyclization of oxidized intermediate $\mathrm{Os}$ (VIII) $15_{[o x]}$ and intermolecular osmylation of $E$-but-2-ene ( $E$-but-2-ene is a model for diene 12).

Under Upjohn osmium-catalyzed dihydroxylation conditions, reoxidation of Os(VI) glycolates is inferred by the observation of second cycle osmylation. ${ }^{19}$ Therefore, we considered whether Os(VIII) trioxoglycolate $\mathbf{1 5}_{[\mathbf{o x}]}$ would enter the second cycle in preference to undergoing cyclization using E-but-2-ene as a model for diene 12 (Figure 7). Intermolecular osmylation of $E$-but2-ene is found to give Os(VI) bis glycolate $\mathbf{2 0}$ as an exergonic reaction $\left(\Delta \mathrm{G}_{\mathrm{osm}}=-76.0 \mathrm{kcal} / \mathrm{mol}\right)$ with a barrier of $5.3 \mathrm{kcal} / \mathrm{mol}$, indicating that second cycle osmylation is kinetically favored over cyclization of $\mathbf{1 5} 5_{[\mathbf{o x}]}$. This is consistent with the experimental outcome of Oscatalyzed reactions of dienes using NMO in the absence of acid. ${ }^{9 c, 15}$

\section{Summary of $\mathrm{Os}(\mathrm{VI})$ and $\mathrm{Os}(\mathrm{VIII})$ pathways}

Experimentally, efficient oxidative cyclization of 1,5dienes is achieved under conditions developed by Donohoe's group, where an excess of strong acid is used. Isolated Os(VI) glycolate intermediates were also shown to cyclize upon exposure to acid. Our calculations are consistent with these results where Os(VI) dioxoglycolate 15 undergoes cyclization by way of the protonated intermediate $\mathbf{1 5}_{\mathrm{H}^{+}}$with a low calculated barrier of $2.1 \mathrm{kcal} / \mathrm{mol}$ as an exergonic process.

When NMO is present, and under acidic conditions, formation of the protonated Os(VI) NMO complex $15_{\mathrm{H}^{+}}{ }_{\mathrm{NMO}}$ is found to be strongly favored. The protonated complex may undergo cyclization with a moderate activation energy $\left(\mathbf{1 5}_{\mathrm{H}^{+}} \mathrm{NMO}^{\rightarrow} \mathbf{1 7}_{\mathrm{H}^{+}}{ }_{\mathrm{NMO}}, \Delta \mathrm{G}^{\ddagger}=18.5\right.$ $\mathrm{kcal} / \mathrm{mol}$ ). Significantly, there is a substantial barrier to reoxidation under acidic conditions $\left(\mathbf{1 5}_{\mathrm{H}^{+}} \mathrm{NMO} \rightarrow \mathbf{1 5}_{[\mathrm{ox}]}+\right.$ 
NMM- $\mathrm{H}^{+}, \Delta \mathrm{G}^{\ddagger}=61.4 \mathrm{kcal} / \mathrm{mol}$ ), and THF formation will outpace oxo-transfer according to our calculations.

Under Piccialli's conditions $\left(\mathrm{OsO}_{4} / \mathrm{NaIO}_{4}\right.$ in DMF), where strong acid has not been deliberately added, both oxidative cyclization and second cycle products were reported (Scheme 2a). ${ }^{9 \mathrm{c}}$ In this case periodic acid may well be present, and therefore, acid-catalyzed cyclization of Os(VI) intermediates remains feasible. However, it is plausible for the first intermediate $\mathbf{1 5}$ to undergo periodate oxidation to Os(VIII) trioxoglycolate $\mathbf{1 5}_{\text {[ox] }}$ under these weakly acidic conditions. The resulting Os(VIII) trioxoglycolate $\mathbf{1 5}_{\text {[ox] }}$ can enter other reaction manifolds such as intermolecular osmylation $\left(\Delta \mathrm{G}^{\ddagger}=5.3 \mathrm{kcal} / \mathrm{mol}\right.$, $\Delta \mathrm{G}_{\mathrm{r}}=-76.0 \mathrm{kcal} / \mathrm{mol}$ ), or undergo acid-catalyzed cyclization via Os(VIII) trioxoglycolate $\mathbf{1 5}_{[\mathbf{l o x}] \mathbf{H}^{+}}$. Finally, under Upjohn conditions $\left(\mathrm{OsO}_{4} / \mathrm{NMO}\right)$, where acid is absent, second cycle osmylation is calculated to be preferred over cyclization, leading exclusively to normal dihydroxylation products, which is indeed the experimental outcome.

Frontier molecular orbital analysis of the SRS

Table 1. Calculated FMO energies for Os(VI) and Os(VIII) glycolates and free energies of activation for their corresponding TS's.

\begin{tabular}{|c|c|c|c|}
\hline intermediate & $\begin{array}{l}\text { LUMO } \\
(\mathrm{eV})\end{array}$ & $\begin{array}{l}\text { energy } \\
\text { gap }(\mathrm{eV})\end{array}$ & $\begin{array}{l}\Delta \mathrm{G}^{\ddagger} \\
(\mathrm{kcal} / \mathrm{mol})\end{array}$ \\
\hline $15_{\text {NMO }}$ & -1.5 & 6.0 & 36.0 \\
\hline $15_{\mathrm{H} 2 \mathrm{O}}$ & -1.6 & 6.6 & 29.2 \\
\hline 15 & -2.3 & 5.7 & 25.2 \\
\hline $15_{\mathrm{H}^{+}} \mathrm{NMO}$ & -2.6 & 5.5 & 18.5 \\
\hline $15^{\prime}{ }^{+}{ }^{+}{ }$ & -2.6 & 5.4 & 19.9 \\
\hline $15_{\text {[ox] }}$ & -3.3 & 4.8 & 11.8 \\
\hline $15^{\prime}{ }_{\mathrm{H}^{+}}$ & -3.6 & 4.6 & 15.5 \\
\hline $15_{\mathrm{H}}+\mathrm{H} 2 \mathrm{O}$ & -3.5 & 4.6 & 11.7 \\
\hline $15 \mathrm{H}^{+}$ & -4.1 & 4.1 & 2.1 \\
\hline 15 $_{[\mathrm{ox}] \mathrm{H}^{+}}$ & -4.9 & 3.6 & 9.2 \\
\hline $15_{[0 x] \mathrm{H}^{+}}$ & -5.5 & 3.1 & 5.0 \\
\hline
\end{tabular}

To understand the influence of additives and reoxidation on the SRS, FMO's were examined (Table 1). FMOs calculated for the intermediate Os(VI) and Os(VIII) glycolates show HOMO's mainly localized on the electron-rich alkene (donor) and LUMO's predominantly located on Os oxo functionality (acceptor, Figure 8).

Some general trends are clearly evident; ligand coordination $\left(\mathrm{H}_{2} \mathrm{O}\right.$ or $\left.\mathrm{NMO}\right)$ to Os glycolates has the effect of increasing LUMO energies (reduced electrophilicity), whereas protonation and oxidation both lead to attenuated LUMO energies (increased electrophilicities). Protonation promotes the SRS in all cases, and the smallest HOMO-LUMO energy gaps are seen for the more electrophilic Os glycolates (e.g. $15_{\mathbf{H}^{+}}$and $\mathbf{1 5}_{[\mathbf{o x}] \mathrm{H}^{+}}$). The lowest barrier to cyclization is for the protonated Os(VI) dioxoglycolate $\mathbf{1 5}_{\mathrm{H}^{+}}$, despite a larger HOMO-LUMO energy gap than $\mathbf{1 5}_{[\mathbf{o x}] \mathrm{H}^{+}}$. The very low barrier to cyclisation of the protonated Os(VI) species $\mathbf{1 5}_{\mathrm{H}^{+}}\left(\Delta \mathrm{G}^{\ddagger}=\right.$ $2.1 \mathrm{kcal} / \mathrm{mol}$ ) may be attributed to favorable orbital overlap arising from the tetrahedral TS geometry, while Os(VIII) TS $\mathbf{1 6}_{[\mathbf{o x}] \mathbf{H}^{+}}$may suffer increased distortion and steric interactions. This proposal is supported through distortion/interaction analysis of the SRS TS's (see Supporting Information for details). ${ }^{28,29}$

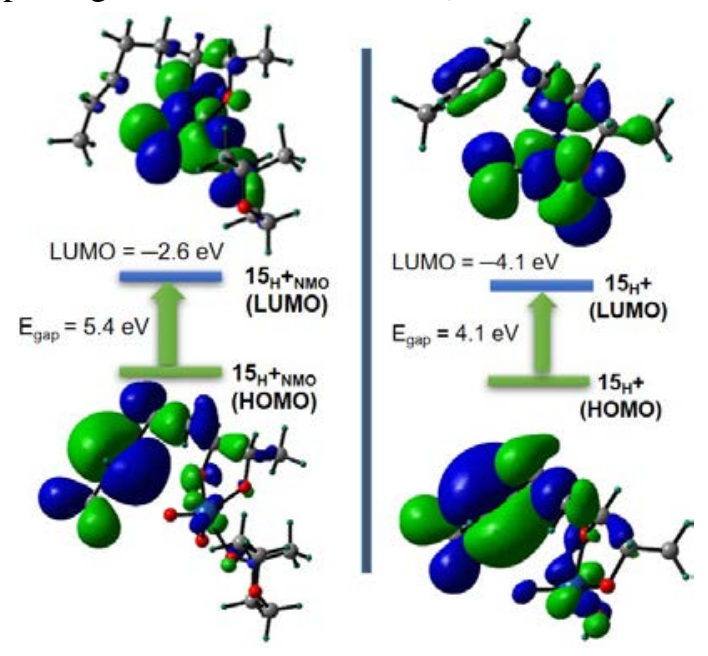

Figure 8. Visualization (0.02 isovalue surface) of the HOMO's and LUMO's for the Os(VI) glycolates $15_{\mathrm{H}^{+}}$ and $15^{+}{ }^{+}$NMO.

\section{Completing the catalytic cycle}

Calculations reported here support cyclization of protonated Os(VI) dioxoglycolate $\mathbf{1 5}_{\mathrm{H}^{+}}$under acidic condi-

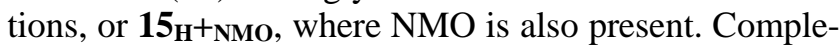
tion of a catalytic cycle requires release of THF diol $\mathbf{1 3}$ and a process for regenerating an Os(VIII) species capable of propagating osmylation of diene 12. Direct pathways entail oxidation/hydrolysis of Os(IV) diolate $\mathbf{1 7}_{\mathrm{H}^{+}}{ }^{\text {NMo }}$ to release THF-diol 13 and Os at a higher oxidation level (see below). An intriguing alternative is also considered where an Os (VIII) THF-diolate could engange in osmylation of another substrate molecule 12, in a process similar to the "second cycle" in dihydroxylation (See Figure 10 and SI).

Oxidation of Os(IV) THF diolates to Os(VI) is considered first (Figure 9). Calculations show coordination of NMO to protonated Os(IV) THF-diolate $\mathbf{1 7}_{\mathbf{H}^{+}}$to be favored $(\Delta \mathrm{G}=-28.7 \mathrm{kcal} / \mathrm{mol})$ under acidic conditions. Thus, $\mathbf{1 7}_{\mathbf{H}^{+}}{ }$Mo is a common intermediate from cyclization of $\mathbf{1 5}_{\mathbf{H}^{+}}$followed by NMO coordination, or directly from cyclization of $15_{\mathrm{H}^{+}} \mathrm{NMO}$. 


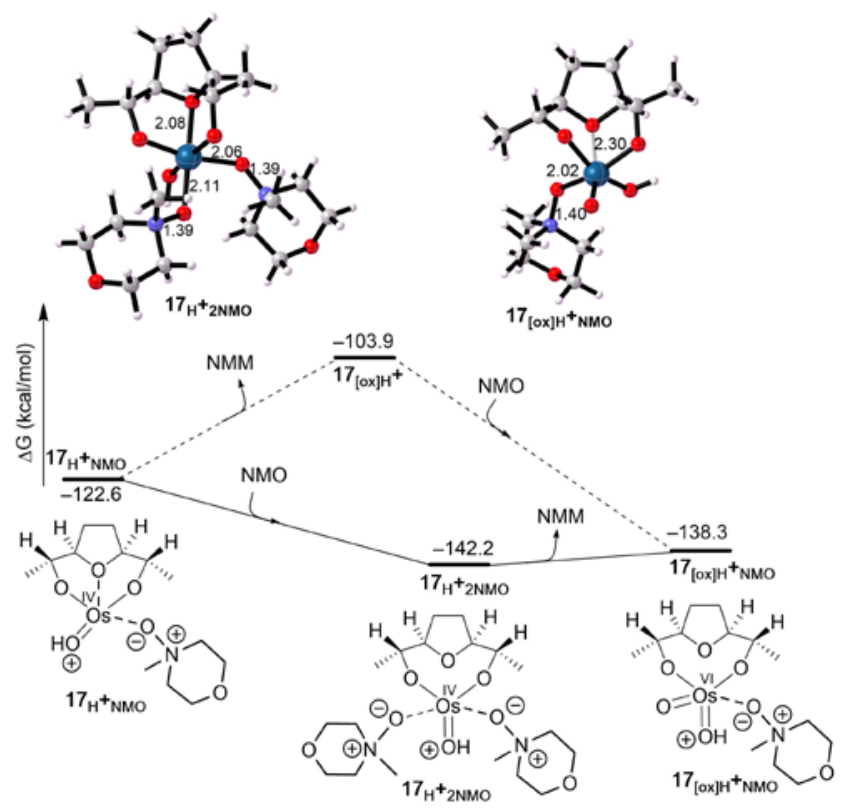

Figure 9. Computational evaluation of the oxidation of Os(IV) THF-diolate to liganded Os(VI) THF-diolate.

Oxo-transfer within the protonated Os(IV) NMO complex to release $\mathbf{1 7}_{[\mathbf{o x}] \mathrm{H}^{+}}$and NMM is endergonic $(\Delta \mathrm{G}=18.7 \mathrm{kcal} / \mathrm{mol})$. Instead, coordination of a second NMO to $\mathbf{1 7}_{\mathrm{H}^{+}}{ }_{\mathrm{NMO}}$, giving octahedral Os(IV) THFdiolate $\mathbf{1 7}_{\mathrm{H}^{+}}{ }_{\text {2NMo }}(\Delta \mathrm{G}=-19.6 \mathrm{kcal} / \mathrm{mol})$, precedes oxotransfer en route to $\mathrm{Os}(\mathrm{VI})$ species $\mathbf{1 7}_{[\mathbf{o x}] \mathrm{H}^{+}}{ }_{\mathrm{NMO}}$ and NMM as a modestly endergonic step. ${ }^{26}$

Without acid, the corresponding oxidation of $\mathbf{1 7}$ to $\mathbf{1 7}_{\text {[ox] }}$ is an energetically favorable process $(\Delta \mathrm{G}=-12.3$ $\mathrm{kcal} / \mathrm{mol}$ ). In acid, protonation of $\mathbf{1 7}_{\mathrm{NMO}}$ to give the NMO complex $17_{\mathrm{H}^{+}}{ }_{\mathrm{NMO}}$ renders its metal center more electron deficient. It is therefore reasonable that oxotransfer, arising from dissociation of the $\mathrm{N}-\mathrm{O}$ bond, is less favorable in $\mathbf{1 7}_{\mathrm{H}^{+}}{ }_{\mathrm{NMO}}$. A more detailed discussion of reoxidation of Os(IV) to Os(VIII), with and without acid, is provided in Supporting Information.
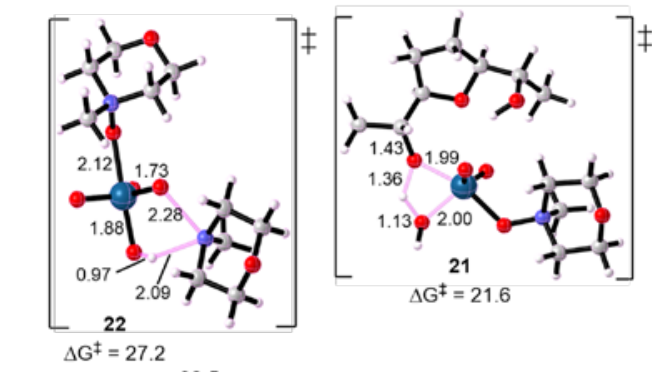

$\Delta \mathrm{G}^{\ddagger}=21.6$

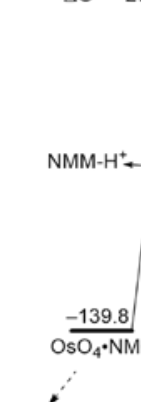

$\frac{-98.5}{22}$

osmylation

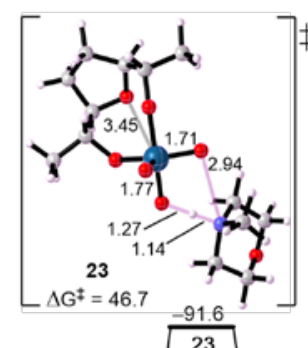

$-91.6$
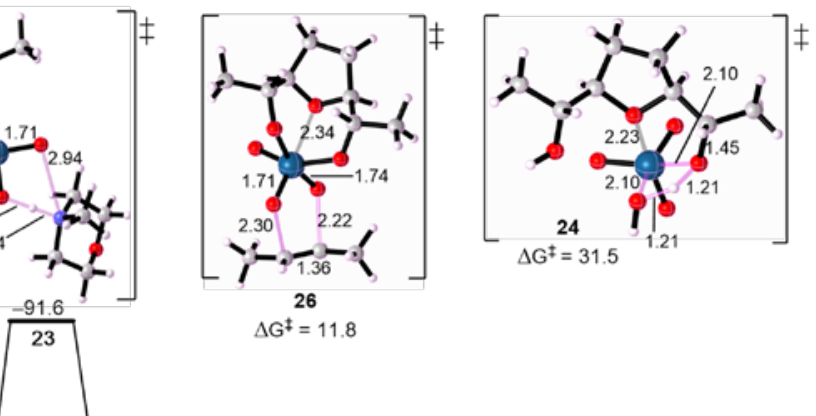

$\Delta \mathrm{G}^{\ddagger}=11$.

hydrolysis - oxidation :" oxidation - hydrolysis
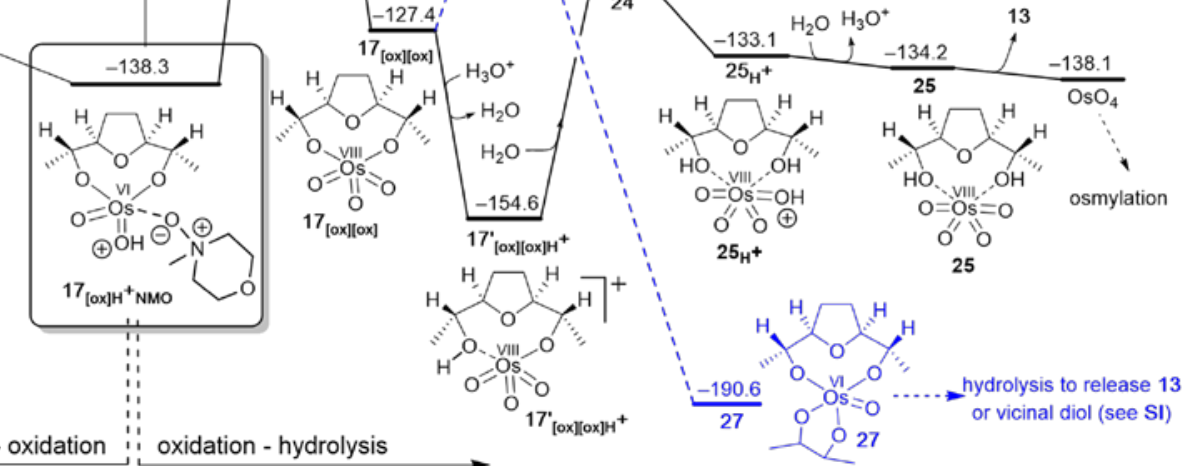

Figure 10. Computational evaluation of reaction manifolds from protonated Os(VI) THF-diolate $17_{[\mathrm{Iox}] \mathrm{H}}{ }^{+} \mathrm{NMO}$, corresponding to hydrolysis then oxidation or oxidation followed by hydrolysis. The possibility of Os(VIII) diolate participating in further osmylation is also shown using $E$-but-2-ene as a model for 12 (blue pathway).

Further oxidation (Os(VI) $\rightarrow \mathrm{Os}(\mathrm{VIII})$ ) and hydrolysis of $\mathbf{1 7}_{[\mathbf{[ o x}] \mathrm{H}^{+}}{ }_{\mathrm{NMo}}$ to release $\mathrm{OsO}_{4}$ and THF diol $\mathbf{1 3}$ is indicated to be rate-limiting from our calculations (Figure 10). Oxidation and hydrolysis steps were considered in either order, showing good overall agreement thermodynamically as approximately thermoneutral processes from $1_{[\mathbf{o x}] \mathrm{H}^{+}}{ }_{\mathrm{NMO}}$. Oxo-transfer within the protonated Os(VI) NMO complex $\mathbf{1 7}_{[\mathbf{o x}] \mathrm{H}^{+}}{ }_{\text {NMo }}$ (via TS 23 ) presents a comparatively higher barrier compared to hydrolytic release of THF diol 13 and $\mathrm{NMO} \cdot \mathrm{OsO}_{3} \mathrm{H}^{+}$. The latter $\mathrm{Os}(\mathrm{VI})$ species is oxidized to $\mathrm{OsO}_{4} \bullet \mathrm{NMO}$ by $\mathrm{NMO}$ with release of the protonated amine $\mathrm{NMM}-\mathrm{H}^{+}$. $\mathrm{OsO}_{4} \cdot \mathrm{NMO}$ has been isolated and characterized by Bailey et al. and our calculations are consistent with weak complexation of the $N$-oxide ligand $(\Delta \mathrm{G}=-1.6 \mathrm{kcal} / \mathrm{mol}){ }^{30}$ It is interesting to note that Os(VIII) trioxodiolate $\mathbf{1 7}_{\text {[ox][ox] }}$ is a 
competent osmylating agent capable of reaction with another molecule of diene 13, considered here using $E$ but-2-ene (Figure 10, blue pathway). Indeed, this "second cycle-like" process could proceed with a modest barrier of $11.8 \mathrm{kcal} / \mathrm{mol}$ to afford tetraester $\mathbf{2 8}$, as an exergonic reaction $(-63.2 \mathrm{kcal} / \mathrm{mol})$. However, access to this "second cycle" should be supressed under strongly acidic conditions due to the high calculated barrier $\left(\Delta \mathrm{G}^{\ddagger}\right.$ $=46.7 \mathrm{kcal} / \mathrm{mol}$ ) to oxo transfer within NMO complex

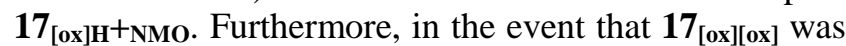
formed, hydrolysis via $\mathbf{1 7}_{\left[{ }_{[0 x]}[\mathbf{o x}] \mathrm{H}^{+}\right.}$should outpace osmylation. For consideration of hydrolysis of $\mathbf{2 8}$ see Supporting Information.

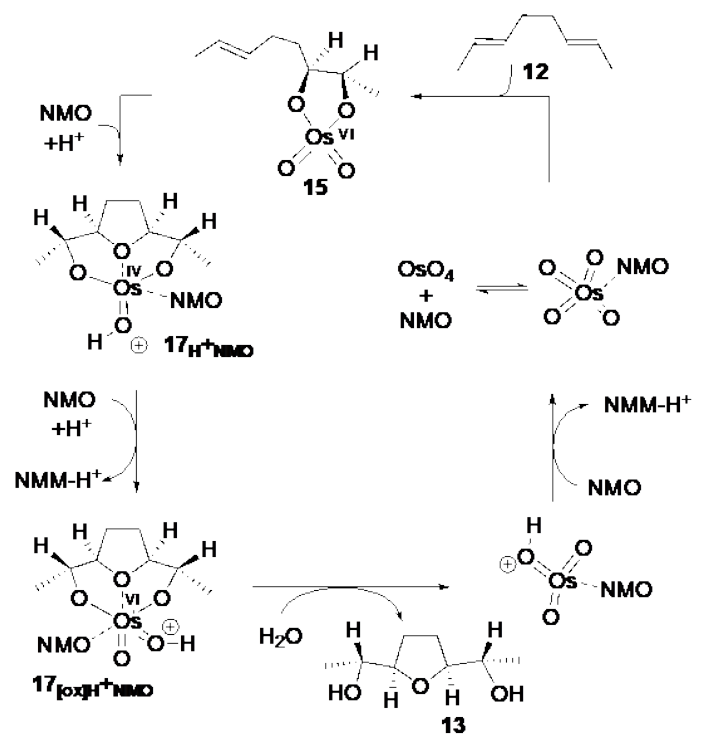

Figure 11. Proposed catalytic cycle for the Os-catalyzed oxidative cyclization of 1,5-diene 12 in the presence of Bronsted acid.

On the basis of these results, and under strongly acidic conditions, osmium-catalyzed oxidative cyclization of 1,5-diene 12 is likely to involve $\mathrm{OsO}_{4}$ as the catalytic species (Figure 11). Protonation of an oxo ligand of the Os(VI) glycolate $\mathbf{1 5}$ is an essential feature of the SRS, promoting cyclization and coordination of NMO. Reoxidation of Os(IV) oxoTHF diolate $\mathbf{1 7}_{\mathbf{H}^{+}}{ }_{\text {NMO }}$ to Os(VI) dioxoTHF diolate is found to proceed by way of the protonated bis NMO complex $\mathbf{1 7}_{\mathbf{H}^{+}}{ }_{2 \mathrm{NMO}}$. Addition of water to $\mathrm{Os}(\mathrm{VI})$ intermediate $\mathbf{1 7}{ }_{[\mathbf{o x}] \mathrm{H}^{+}}{ }_{\mathrm{NMo}}$ enables release of the THF diol 13 and $\mathrm{OsO}_{3}$ as its protonated NMO complex, which is oxidised to $\mathrm{OsO}_{4}{ }^{\bullet} \mathrm{NMO}$ and $\mathrm{NMMH}^{+}$by another equivalent of NMO.

\section{CONCLUSIONS}

The mechanism of the osmium mediated oxidative cyclization of 1,5-dienes to produce THF-diols has been explored using DFT calculations, leading to an understanding of the key role of acid in promoting the cyclization step (SRS). Calculations show that protonation of the Os(VI) dioxoglycolate intermediate provides a kinetically favorable pathway $\left(\mathbf{1 5} \rightarrow \mathbf{1 5}_{\mathrm{H}^{+}} \rightarrow \mathbf{1 7} \mathbf{H}^{+}\right)$compared to reoxidation $\left(\mathbf{1 5} \rightarrow \mathbf{1 5}_{\text {[ox] }} \rightarrow \mathbf{1 7} 7_{\text {[ox] }}\right)$ using NMO as the terminal oxidant. Protonation of Os(VI) dioxoglycolate $\mathbf{1 5}_{\mathrm{H}^{+}}$strongly favors coordination of NMO to Os and the resulting complex $\mathbf{1 5}_{\mathrm{H}^{+}}{ }_{\mathrm{NMO}}$ undergoes cyclization in preference to oxo-transfer. Significantly, our calculations are consistent with experimental data for osmiummediated and catalyzed reactions which require an excess of TFA or CSA and NMO, but not proceed using NMO alone. These experimental results cannot be reconciled with the conclusion of a previous DFT investigation that cyclization occurs by an Os(VIII) trioxoglycolate $\mathbf{1 7}_{\text {[ox]. }}$. Furthermore, our calculations show that in the absence of acid, Os(VIII) intermediate $\mathbf{1 7}_{\text {[ox] }}$ favors second cycle osmylation over cyclization. This is indeed the observed experimental outcome when 1,5-dienes are subjected to $\mathrm{OsO}_{4} / \mathrm{NMO}$. In addition, the DFT results for the SRS are also consistent with the related Os-catalyzed oxidative cyclization of dihydroxyalkenes which proceed through an $\mathrm{Os}(\mathrm{VI}) / \mathrm{Os}(\mathrm{IV}) / \mathrm{Os}(\mathrm{VI})$ cycle, rather than Os(VIII)/Os(VI)/Os(VIII).

A catalytic cycle is proposed for oxidative cyclization of 1,5-dienes under acidic conditions, using osmium with NMO as the co-oxidant. Following the SRS $\left(15 \rightarrow 15_{\mathrm{H}^{+}} \rightarrow \mathbf{1 7}_{\mathrm{H}^{+}}{ }_{\mathrm{NMO}}\right)$, oxidation and hydrolytic release of the THF-diol product $\mathbf{1 3}$ and $\mathrm{NMO} \cdot \mathrm{OsO}_{3} \mathrm{H}^{+}$are found to be relatively slow steps. Another equivalent of NMO facilitates further oxidation to $\mathrm{NMO} \cdot \mathrm{OsO}_{4}$ and $\mathrm{NMMH}^{+}$.

Overall, the present study gives significant insight into this important synthetic method, and the intricacies of acid-catalysis on reoxidation, hydrolysis and second cycle processes in Os-catalyzed oxidations.

\section{EXPERIMENTAL SECTION}

Computational Details. All calculations were performed using Gaussian 09, ${ }^{31}$ using the hybrid metageneralized gradient approximation functional M06$2 \mathrm{X}^{32,33}$ with the augmented correlation-consistent polarized valence double- $\zeta$ (DZ) basis set (aug-cc-pVDZ) ${ }^{34}$ ${ }^{36}$ for $\mathrm{C}, \mathrm{H}, \mathrm{O}$, and N. Hay-Wadt VDZ $(\mathrm{n}+1)$ ECP was used for Os in both the B3LYP and M06-2X functional calculations. ${ }^{37}$ All minima intermediates were verified by the absence of negative eigenvalues in the vibrational frequency analysis. Transition state structures were found using the Berny algorithm, ${ }^{38,39}$ and verified by vibrational analysis. The transition states were visualized by animating the negative eigenvector coordinate. In order to determine the minimum energy path (MEP) on the potential energy surface (PES), intrinsic reaction coordinate (IRC) calculations, by defining the phase for the transition vector motion along the path, were performed for the identified transition states using the Hessian-based Predictor-Corrector integrator to confirm the reaction path proceeding in both directions (reactant and product), in which the Hessian was recomputed every 3 predictor steps with a step size along the reaction path of 0.05 Bohr. ${ }^{40-42}$ Gibbs free energies $(\Delta G)$ and enthalpies $(\Delta \mathrm{H})$ were obtained through thermochemical analysis based on vibrational frequencies. All energies 
reported in this paper are Gibbs free energies or enthalpies at $298.15 \mathrm{~K}$ (otherwise mentioned) using unscaled frequencies. The effect of solvent was included via the solvation model based on density (IEFPCM-SMD).$^{43}$ The solvation model (using acetone as a representative solvent medium otherwise mentioned) was incorporated only for the M06-2X functional calculations. All energies are in $\mathrm{kcal} / \mathrm{mol}$ except Entropies which are given in units of $\mathrm{cal} / \mathrm{K} * \mathrm{~mol}$. All activation free energies are quoted relative to infinitely separated reagents. Optimized structures are illustrated using CYLview. ${ }^{44}$

\section{ASSOCIATED CONTENT}

Supporting Information. Additional calculated reaction pathways, comparisons with experimental data, comparison of results using B3LYP and M06-2X functionals, MD simulations, distortion-interaction analyses of SRSs, Cartesian coordinates, absolute energies for reported structures (pdf).

The Supporting Information is available free of charge on the ACS Publications website.

brief description (file type, i.e., PDF)

brief description (file type, i.e., PDF)

\section{AUTHOR INFORMATION}

\section{Corresponding Author}

*rcb1@soton.ac.uk

\section{Present Addresses}

$\dagger$ Faculty of Dentistry, University of Al-Ameed, Karbala P.O. No: 198, Iraq

\section{Author Contributions}

The manuscript was written through contributions of all authors.

\section{ACKNOWLEDGMENT}

The authors acknowledge financial support from EPSRC (EP/K039466/1), the office of the Iraqi Prime Minister (HCED/Iraq) for a scholarship (AAH). Calculations reported in this work were carried out on the University of Southampton Iridis4 supercomputer.

\section{REFERENCES}

1. For selected reviews of bioactive natural products containing tetrahydrofurans. Polyether ionophores: (a) Rutkowski, J.; Brzezinski, B. Structures and Properties of Naturally Occurring Polyether Antibiotics. Biomed. Res. Int. 2013, Article ID 162513, doi:10.1155/2013/162513. (b) Huczynski, A. Polyether ionophorespromising bioactive molecules for cancer therapy. Bioorg. Med. Chem. Lett. 2012, 22, 7002-7010. (c) Kevin, D. A.; Meujo, D. A. F.; Hamann, M. T. Polyether ionophores: broad-spectrum and promising biologically active molecules for the control of drug-resistant bacteria and parasites. Expert Opin. Drug Discov. 2009, 4, 109-146. Annonaceous Acetogenins: (d) Liaw, C. C.; Liou, J. R.; Wu, T. Y.; Chang, F. R.; Wu, Y. C. Acetogenins from Annonaceae. Prog. Chem. Org. Nat. Prod. 2016, 101, 113-230. THF-containing macrolides: (e)
Lorente, A.; Lamariano-Merketegi, J.; Albericio, F.; Alvarez, M. Tetrahydrofuran-containing macrolides: a fascinating gift from the deep sea. Chem. Rev. 2013, 113, 4567-4610.

2. For selected reviews of tetrahydrofuran synthesis: (a) de la Torre, A.; Cuyamendous, C.; Bultel-Ponce, V.; Durand, T.; Galano, J. M.; Oger, C. Recent advances in the synthesis of tetrahydrofurans and applications in total synthesis. Tetrahedron 2016, 72, 5003-5025. (b) Rainier, J. D. Synthesis of Substituted Tetrahydrofurans. In Synthesis of Saturated Oxygenated Heterocycles I: 5- and 6-Membered Rings, Topics Heterocyclic Chem. 2014, 35, 1-41. (c) Jalce, G.; Franck, X.; Figadère, B. Diastereoselective synthesis of 2,5-disubstituted tetrahydrofurans. Tetrahedron Asymmetry 2009, 20, 2537-2581. (d) Wolfe, J. P.; Hay, M. B. Recent advances in the stereoselective synthesis of tetrahydrofurans. Tetrahedron 2007, 63, 261-290. (e) Elliott, M. C. Saturated oxygen heterocycles. J. Chem. Soc. Perkin Trans. 1 2002, 2301-2323. (f) Faul, M. M.; Huff, B. E. Strategy and methodology development for the total synthesis of polyether ionophore antibiotics. Chem. Rev. 2000, 100, 2407-2473. (g) Boivin, T. L. B. Synthetic routes to tetrahydrofuran, tetrahydropyran, and spiroketal units of polyether antibiotics and a survey of spiroketals of other natural-products. Tetrahedron 1987, 43, 3309-3362.

3. For reviews: (a) Adrian, J.; Gross, L. J.; Stark, C. B. W. The direct oxidative diene cyclization and related reactions in natural product synthesis. Beilstein J. Org. Chem. 2016, 12, 2104-2123. (b) Sheikh, N. S. Comparative perspective and synthetic applications of transition metal mediated oxidative cyclisation of 1,5-dienes towards cis-2,5-disubstituted tetrahydrofurans. Org. Biomol. Chem. 2014, 12, 9492-9504. (c) Piccialli, V. Ruthenium tetroxide and perruthenate chemistry. Recent advances and related transformations mediated by other transition metal oxo-species. Molecules 2014, 19, 6534-6582. (d) Pilgrim, B. S.; Donohoe, T. J. Osmium-catalyzed oxidative cyclization of dienes and their derivatives. J. Org. Chem. 2013, 78, 2149-2167. (e) Piccialli, V. Oxidative cyclization of dienes and polyenes mediated by transition-metal-oxo species. Synthesis 2007, 2585-2607.

4. Closely related oxidative cyclizations of 1,4-dienes, 1,6-dienes and 1,7-dienes have also been reported. 1,4-dienes: (a) Travis, B.; Borhan, B. Oxidative cyclization of 1,4-dienes to yield 2,3,5trisubstituted tetrahydrofuran-diols. Tetrahedron Lett. 2001, 42, 7741-7745. 1,6-dienes: (b) Roth, S.; Stark, C. B. W. Efficient oxidative cyclization of 1,6-Dienes: a highly diastereoselective entry to substituted tetrahydropyrans. Angew. Chem. Int. Ed. 2006, 45, 6218-6221. (c) Cecil, A. R. L.; Brown, R. C. D. Stereoselective synthesis of cis-2,6-bis-hydroxyalkyl-tetrahydropyrans by the permanganate promoted oxidative cyclisation of 1,6-dienes. Tetrahedron Lett. 2004, 45, 7269-7271. (d) Piccialli, V. $\mathrm{RuO}_{4}$ catalysed oxidative cyclisation of 1,6-dienes to trans-2,6bis(hydroxymethyl)tetrahydropyranyldiols. A novel stereoselective process. Tetrahedron Lett. 2000, 41, 3731-3733. 1,7-dienes: (e) Piccialli, V.; Borbone, N.; Oliviero, G. Ruthenium-catalyzed oxidative cyclization of 1,7-dienes. A novel diasteroselective synthesis of 2,7-disubstituted trans-oxepane diols. Tetrahedron Lett. 2007, 48, 5131-5135.

5. For selected examples. (a) Al Hazmi, A. M.; Sheikh, N. S.; Bataille, C. J. R.; Al-Hadedi, A. A. M.; Watkin, S. V.; Luker, T. J.; Camp, N. P.; Brown, R. C. D. trans-2-Tritylcyclohexanol as a chiral auxiliary in permanganate-mediated oxidative cyclization of 2methylenehept-5-enoates: application to the synthesis of trans-(+)linalool oxide.Org. Lett. 2014, 16, 5104-5107. (b) Brown, R. C. D.; Kocienski, P. J. A synthesis of salinomycin 1. Synthesis of key fragments. Synlett 1994, 415-417. (c) Walba, D. M.; Wand, M. D.; Wilkes, M. C. Stereochemistry of the permanganate oxidation of 1,5dienes. J. Am. Chem. Soc. 1979, 101, 4396-4397.

6. Brown, R. C. D.; Keily, J. F. Asymmetric permanganatepromoted oxidative cyclization of 1,5-dienes by using chiral phasetransfer catalysis. Angew. Chem. Int. Ed. 2001, 40, 4496-4498.

7. For examples of cis-selective oxidative cyclizations of dihydroxyalkenes using Ru, Os or Cr oxo-species. Ru oxo-species: (a) Cheng, H.; Stark, C. B. W. A double donor-activated ruthenium(VII) catalyst: Synthesis of enantiomerically pure THF-diols. Angew. Chem. Int. Ed. 2010, 49, 1587-1590. (b) Gohler, S.; Stark, C. B. W. Catalytic diastereo- and position selective oxidative mono-cyclization 
of 1,5,9-trienes and polyenes. Org. Biomol. Chem. 2007, 5, 16051614. Os oxo-species: (c) Donohoe, T. J.; Wheelhouse, K. M. P.; Lindsay-Scott, P. J.; Glossop, P. A.; Nash, I. A.; Parker, J. S. Pyridine- $N$-oxide as a mild reoxidant which transforms osmiumcatalyzed oxidative cyclization. Angew. Chem. Int. Ed. 2008, 47, 2872-2875. (d) Donohoe, T. J.; Butterworth, S. Oxidative cyclization of diols derived from 1,5-dienes: Formation of enantiopure cistetrahydrofurans by using catalytic osmium tetroxide; Formal synthesis of (+)-cis-solamin. Angew. Chem. Int. Ed. 2005, 44, 47664768. Cr oxo-species: (e) Corey, E. J.; Ha, D. C. Total synthesis of venustatriol. Tetrahedron Lett 1988, 29, 3171-3174. (f) Walba, D. M.; Stoudt, G. S. Oxidative cyclization of 5,6-dihydroxyalkenes promoted by $\mathrm{Cr}(\mathrm{VI})$ oxo species: A novel cis-2,5-disubstituted tetrahydrofuran synthesis. Tetrahedron Lett 1982, 23, 727-730. (g) Hammock, B. D.; Gill, S. S.; Casida, J. E. Synthesis and morphogenetic activity of derivatives and analogs of aryl geranyl ether juvenoids. J. Agr. Food Chem. 1974, 22, 379-385.

8. (a) Baldwin, J. E.; Crossley, M. J.; Lehtonen, E.-M. M Stereospecificity of oxidative cycloaddition reactions of 1,5-dienes. $J$. Chem. Soc. Chem. Commun. 1979, 918-920. (b) Klein, E.; Rojahn, W. Die permanganatoxydation von 1,5-dienverbindungen. Tetrahedron 1965, 21, 2353-2358.

9. (a) Donohoe, T. J.; Butterworth, S. A general oxidative cyclization of 1,5-dienes using catalytic osmium tetroxide. Angew. Chem. Int. Ed. 2003, 42, 948-951. (b) Donohoe, T. J.; Winter, J. J. G.; Helliwell, M.; Stemp, G. Hydrogen bonding control in the oxidative cyclisation of 1,5-dienes. Tetrahedron Lett. 2001, 42, 971974. (c) de Champdore, M.; Lasalvia, M.; Piccialli, V. OsO4Catalyzed oxidative cyclization of geranyl and neryl acetate to cis2,5-bis(hydroxymethyl)tetrahydrofurans Tetrahedron Lett. 1998, 39, 9781-9784.

10. The original discovery of oxidative cyclizations of 1,5-dienes with $\mathrm{RuO}_{4}$ reported mixtures of cis and trans THF-diol products. (a) Carlsen, P. H. J.; Katsuki, T.; Martin, V. S.; Sharpless, K. B. A greatly improved procedure for ruthenium tetraoxide catalyzed oxidations of organic compounds. J. Org. Chem. 1981, 46, 39363938. For development of conditions for cis-selective oxidative cyclizations. (b) Roth, S.; Göhler, S.; Cheng, H.; Stark, C. B. W. A highly efficient procedure for ruthenium tetroxide catalyzed oxidative cyclizations of 1,5-dienes. Eur. J. Org. Chem. 2005, 4109-4118. (c) Piccialli, V.; Caserta, T. Perruthenate ion. Another metal oxo species able to promote the oxidative cyclisation of 1,5-dienes to 2,5disubstituted cis-tetrahydrofurans. Tetrahedron Lett. 2004, 45, 303308. (d) Piccialli, V.; Cavallo, N. Improved $\mathrm{RuO}_{4}$-catalysed oxidative cyclisation of geraniol-type 1,5-dienes to cis-2,5bis(hydroxymethyl)tetrahydrofuranyldiols. Tetrahedron Lett. 2001, 42, 4695-4699. (e) Albarella, L.; Musumeci, D.; Sica, D. Reactions of 1,5-dienes with ruthenium tetraoxide: stereoselective synthesis of tetrahydrofurandiols. Eur. J. Org. Chem. 2001, 997-1003.

11. For additional selected examples see: (a) Sheikh, N. S. Synthetic endeavours towards oxasqualenoid natural products containing 2,5disubstituted tetrahydrofurans - eurylene and teurilene. Nat. Prod. Rep. 2014, 31, 1088-1100. (b) Donohoe, T. J.; Lipinski, R. M. Interplay of cascade oxidative cyclization and hydride shifts in the synthesis of the ABC spiroketal ring system of pectenotoxin-4. Angew. Chem. Int. Ed. 2013, 52, 2491-2494. (c) Goksel, H.; Stark, C. B. W. Total synthesis of cis-solamin: exploiting the $\mathrm{RuO}_{4}$-catalyzed oxidative cyclization of dienes. Org. Lett. 2006, 8, 3433-3436. (d) Lygo, B.; Slack, D.; Wilson, C. Synthesis of neodysiherbaine. Tetrahedron Lett. 2005, 46, 6629-6632.

12. Much earlier work described an unidentified product formed from attempted bis dihydroxylation of 1,5-dienes. Kötz, A.; Steche, T. On the gradual oxidation of citronellols and geraniols. J. Prakt. Chem. [2] 1924, 107, 193.

13. (a) Aniagyei, A.; Tia, R.; Adei, E. A theoretical study of the mechanisms of oxidation of ethylene by manganese oxo complexes. Dalton Trans. 2013, 42, 14411-14423. (b) Wiberg, K. B.; Wang, Y. G.; Sklenak, S.; Deutsch, C.; Trucks, G. Permanganate oxidation of alkenes. Substituent and solvent effects. Difficulties with MP2 calculations. J. Am. Chem. Soc. 2006, 128, 11537-11544. (c) Ogino, T.; Yaezawa, H.; Yoshida, O.; Ono, M. An experimental and theoretical study on the substituent effect of the permanganate oxidation of styrenes Org. Biomol. Chem. 2003, 1, 2771-2776. (d) Strassner, T.; Busold, M. A density functional theory study on the mechanism of the permanganate oxidation of substituted alkenes. $J$. Org. Chem. 2001, 66, 672-676.

14. Results of DFT calculations support cyclization of an intermediate $\mathrm{Mn}(\mathrm{V})$ diester: Poethig, A.; Strassner, T. The mechanism of the permanganate-promoted oxidative cyclization of 1,5-dienes - A DFT study. Collect Czech Chem. Commun. 2007, 72, 715-727.

15. (a) Vidari, G.; Dapiaggi, A.; Zanoni, G.; Garlaschelli, L. Asymmetric dihydroxylation of geranyl, neryl and trans,transfarnesyl acetates Tetrahedron Lett. 1993, 34, 6485-6488. (b) G. Crispino and K. B. Sharpless, Asymmetric dihydroxylation of squalene. Tetrahedron Lett. 1992, 33, 4273-4274.

16. DFT studies of oxidative cyclization using Os. Poethig, A.; Strassner, T. Stereoselective $\mathrm{OsO}_{4}$-catalyzed oxidative cyclization of 1,5-dienes. J. Org. Chem. 2010, 75, 1967-1973.

17. DFT studies of oxidative cyclization using $\mathrm{RuO}_{4}$. di Dio, P. J.; Zahn, S.; Stark, C. B. W.; Kirchner, B. Understanding selectivities in ligand-free oxidative cyclizations of 1,5-and 1,6-dienes with $\mathrm{RuO}_{4}$ from density functional theory. Z. Naturforsch., B: J. Chem. Sci. 2010, 65, 367-375.

18. (a) Ess, D. H. Distortion, interaction, and conceptual DFT perspectives of $\mathrm{MO}_{4}$-alkene $(\mathrm{M}=\mathrm{Os}$, Re, Tc, Mn) cycloadditions. $J$. Org. Chem. 2009, 74, 1498-1508. (b) Deubel, D. V.; Frenking, G. $[3+2]$ versus $[2+2]$ addition of metal oxides across $C=C$ Bonds. Reconciliation of experiment and theory. Acc. Chem. Res. 2003, 36, 645651. (c) Houk, K. N.; Strassner, T. Establishing the $(3+2)$ mechanism for the permanganate oxidation of alkenes by theory and kinetic isotope effects. J. Org. Chem. 1999, 64, 800-802. (d) DelMonte, A. J.; Haller, J.; Houk, K. N.; Sharpless, K. B.; Singleton, D. A.; Strassner, T.; Thomas, A. A. Experimental and theoretical kinetic isotope effects for asymmetric dihydroxylation. Evidence supporting a rate-limiting "(3+2)" cycloaddition. J. Am. Chem. Soc. 1997, 119, 9907-9908. (e) Pidun, U.; Boehme, C.; Frenking, G. Theory rules out a [2+2] addition of osmium tetroxide to olefins as initial step of the dihydroxylation reaction. Angew. Chem. Int. Ed. 1996, 35, 28172820. (f) Dapprich, S.; Ujaque, G.; Maseras, F.; Lledos, A.; Musaev, D. G.; Morokuma, K. Theory does not support an osmaoxetane intermediate in the osmium-catalyzed dihydroxylation of olefins. J. Am. Chem. Soc. 1996, 118, 11660-11661.

19. (a) Dupau, P.; Epple, R.; Thomas, A. A.; Fokin V. V.; Sharpless, K. B. Osmium-catalyzed dihydroxylation of olefins in acidic media: old process, new tricks. Adv. Synth. Catal., 2002, 344, 421433. (b) Kolb, H. C.; Vannieuwenhze, M. S.; Sharpless, K. B. Catalytic asymmetric dihydroxylation. Chem. Rev. 1994, 94, 24832547. (c) Wai, J. S. M.; Marko, I.; Svendsen, J. S.; Finn, M. G.; Jacobsen, E. N.; Sharpless, K. B. A mechanistic insight leads to a greatly improved osmium-catalyzed asymmetric dihydroxylation process. J. Am. Chem. Soc. 1989, 111, 1123-1125.

20. For validation of the choice of the Functional and basis set see Supporting Information sections 2.1 and 2.2.

21. Calculations were fully optimized in gas phase, then single point corrections were performed with SMD. Further details are provided in the Supporting Information.

22. The calculated activation energy is in good agreement with experimental values: Nelson, D. W.; Gypser, A.; Ho, P. T.; Kolb, H. C.; Kondo, T.; Kwong, H. L.; McGrath, D. V.; Rubin, A. E.; Norrby, P. O.; Gable, K. P.; Sharpless, K. B. Toward an understanding of the high enantioselectivity in the osmium-catalyzed asymmetric dihydroxylation. J. Am. Chem. Soc. 1997, 119, 1840-1858.

23. (a) Michael J. Cleare, M. J.; Hydes, P. C.; Griffith, W. P.; Wright, M. J. Studies on transition-metal oxo- and nitrido-complexes. Part 3. Complexes of osmium tetraoxide with tertiary amines, and their reactions with alkenes. J.C.S. Dalton 1977, 941-944. (b) Subbaraman, L. R.; Subbaraman, J.; Behrman, E. J. Studies on formation and hydrolysis of osmate(VI) esters. Inorg. Chem. 1972, 11, 26212627.

24. For calculations involving high spin pathways see Supporting Information.

25. Tenderholt, A. L.; Hodgson, K. O.; Hedman, B.; Holm, R. H.; Solomon, E. I. Substrate and metal control of barrier heights for oxo 
transfer to Mo and W bis-dithiolene sites. Inorg. Chem. 2012, 51, 3436-3442.

26. Despite considerable effort, we were unable to locate TS's for oxo-transfer from $\mathrm{N}$ to Os in $\mathbf{1 5}_{\mathrm{NMO}}, \mathbf{1 7}_{\mathrm{H}^{+}} \mathrm{NMO}$ or $\mathbf{1 7}_{\mathrm{H}^{+}}{ }_{2 \mathrm{NMO}}$. We do not have an explanation for this, and our analysis relied on the calculated thermodynamic data for these steps.

27. For experimental determination of the reoxidation kinetics for Os(VI) to Os(VIII). (a) Erdik, E.; Kahya, D. Structure-reactivity correlation for the ligand-decelerated catalytic osmium tetraoxide dihydroxylation of alkenes. J. Phys. Org. Chem. 2002, 15, 229-232. (b) Erdik, E.; Kahya, D. Kinetic role of tert-amines in the osmium tetroxide catalyzed trimethylamine $\mathrm{N}$-oxide dihydroxylation of cyclohexene. Int. J. Chem. Kinet. 1997, 29, 359-366. (c) Erdik, E.; Matteson, D. S. Kinetics of osmium tetraoxide catalyzed trimethylamine $N$-oxide oxidations of cyclohexene and $\alpha$-pinene to diols. J. Org. Chem. 1989, 54, 2742-2748.

28. Cioslowski, J. A new population analysis based on atomic polar tensors. J. Am. Chem. Soc. 1989, 111, 8333-8336.

29. (a) Bickelhaupt, F. M.; Houk, K. N. Analyzing reaction rates with the distortion/interaction-activation strain model. Angew. Chem. Int. Ed. 2017, 56, 10070-10086. (b) He, C. Q.; Chen, T. Q.; Patel, A.; Karabiyikoglu, S.; Merlic, C. A.; Houk, K. N. Distortion, tether, and entropy effects on transannular Diels-Alder cycloaddition reactions of 10-18-membered rings. J. Org. Chem. 2015, 80, 11039-11047.

30. Bailey, A. J.; Bhowon, M. G.; Griffith, W. P.; Shoair, A. G. F.; White, A. J. P.; Williams, D. J. Oxo osmium(VIII) complexes in oxidation: crystal structures of $\mathrm{OsO}_{4} \bullet \mathrm{NMO} \quad(\mathrm{NMO}=\mathrm{N}$ methylmorpholine $\mathrm{N}$-oxide) and $\mathrm{OsO}_{4} \cdot \mathrm{NMM}(\mathrm{NMM}=\mathrm{N}$ methylmorpholine), and use of cis- $\left[\mathrm{OsO}_{4}(\mathrm{OH})_{2}\right]^{2-}$ as an oxidation catalyst. J. Chem. Soc., Dalton Trans. 1997, 3245-3250.

31. Frisch, M. J. et al. Gaussian 09, Gaussian, Inc.: Wallingford, CT, USA, 2009.

32. Zhao, Y.; Truhlar, D. G. Applications and validations of the Minnesota density functionals. Chem. Phys. Lett. 2011, 502, 1-13.

33. Zhao, Y.; Truhlar, D. G. The M06 suite of density functionals for main group thermochemistry, thermochemical kinetics, noncova- lent interactions, excited states, and transition elements: two new functionals and systematic testing of four M06-class functionals and 12 other functionals. Theor. Chem. Acc. 2007, 120, 215-241.

34. Dunning, T. H. Gaussian basis sets for use in correlated molecular calculations. I. The atoms boron through neon and hydrogen. $J$. Chem. Phys. 1989, 90, 1007-1023.

35. Kendall, R. A.; Dunning, T. H.; Harrison, R. J. Electron affinities of the first-row atoms revisited. Systematic basis sets and wave functions. J. Chem. Phys. 1992, 96, 6796-6806.

36. Woon, D. E.; Dunning, T. H. Gaussian basis sets for use in correlated molecular calculations. III. The atoms aluminum through argon. J. Chem. Phys. 1993, 98, 1358-1371.

37. Hay, P. J.; Wadt, W. R. Ab initio effective core potentials for molecular calculations. Potentials for K to Au including the outermost core orbitals. J. Chem. Phys. 1985, 82, 299-310.

38. Schlegel, H. B. Optimization of equilibrium geometries and transition structures. J. Comput. Chem. 1982, 3, 214-218.

39. Li, X.; Frisch, M. J. Energy-represented direct inversion in the iterative subspace within a hybrid geometry optimization method. $J$. Chem. Theory Comput. 2006, 2, 835-839.

40. Hratchian, H. P.; Schlegel, H. B. Accurate reaction paths using a Hessian based predictor-corrector integrator. J. Chem. Phys. 2004, 120, 9918-9924.

41. Collins, M. A. Molecular potential-energy surfaces for chemical reaction dynamics. Theor. Chem. Acc. 2002, 108, 313-324.

42. Fukui, K., The path of chemical reactions - the IRC approach. Acc. Chem. Res. 1981, 14, 363-368.

43. Marenich, A. V.; Cramer, C. J.; Truhlar, D. G. Universal solvation model based on solute electron density and on a continuum model of the solvent defined by the bulk dielectric constant and atomic surface tensions. J. Phys. Chem. B 2009, 113, 6378-6396.

44. Legault, C. Y. CYLview, 1.0b; Université de Sherbrooke: Sherbrooke, QC, Canada, 2009; http://www.cylview.org. 


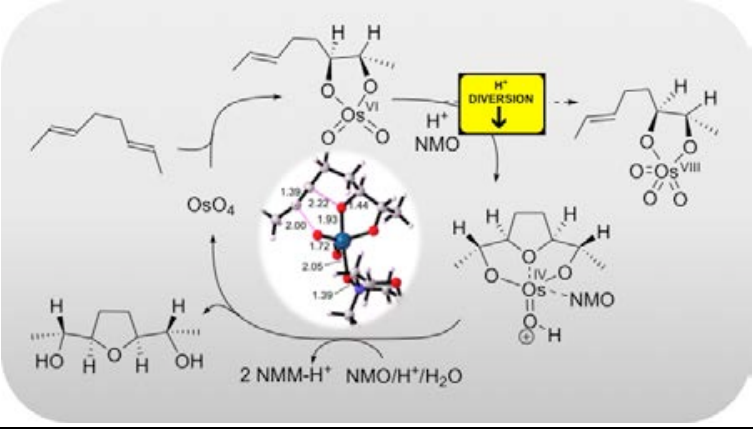

